\title{
Gender Differences in Inflammatory Bowel Disease
}

\author{
Thomas Greuter ${ }^{\mathrm{a}}$ Christine Manser ${ }^{\mathrm{b}}$ Valerie Pittet ${ }^{\mathrm{c}}$ Stephan R. Vavricka ${ }^{\mathrm{a}, \mathrm{d}}$ \\ Luc Biedermann $^{\text {a }}$ on behalf of Swiss IBDnet, an official working group of the
}

\section{Swiss Society of Gastroenterology}

${ }^{a}$ Department of Gastroenterology and Hepatology, University Hospital Zurich, Zurich, Switzerland; bepartment of Medicine, Kantonsspital Frauenfeld, Frauenfeld, Switzerland; ' Institute of Social and Preventive Medicine, University Hospital Lausanne, CHUV, Lausanne, Switzerland; ' Center for Gastroenterology and Hepatology,

Zurich, Switzerland

\section{Keywords}

Disease activity · Disease course · Disease phenotype · Environmental factors · Epidemiology · Extraintestinal manifestations · Fatigue · Gender · Genetics · Inflammatory bowel disease $\cdot$ Psychological factors $\cdot$ Sex

\section{Abstract}

Immune-mediated diseases typically show a female preponderance. Looking at all autoimmune diseases combined, 8 of 10 patients are females. Although not as prominent, gender differences in inflammatory bowel disease (IBD) have been reported for epidemiology, disease presentation, disease course and complications, medical and surgical therapies, adherence, psychosocial functioning, and psychiatric co-disorders. While for some factors evidence is rather good, for others data are conflicting. Gastroenterologists dealing with IBD patients in daily clinical practice should be aware of gender-specific issues for the following reasons: (1) misperception of disease presentation potentially delays IBD diagnosis, which has been shown to have deleterious effects, and (2) awareness of gender-specific symptoms and disease severity allows initiation of early and adequately tailored treatment. This might prevent development of complications. And (3) insights into gender-specific differences in terms of treatment and adherence to treatment can improve disease management and foster a more individualized treatment approach. In this review, we summarize current knowledge about gender-specific differences in IBD and highlight the most clinically relevant aspects.

(c) 2020 S. Karger AG, Base

\section{Introduction}

The influence of the menstrual cycle on inflammatory bowel disease (IBD) course has been identified $>2$ decades ago [1]. So far, most sex-specific IBD studies have focused on pregnancy and childbirth. However, many more gender-specific differences (physiological and psychological) seem to play an important role in IBD [2]. Gender-specific differences in IBD have been reported for disease presentation, disease course and complications, medical and surgical therapies, adherence, psychosocial functioning, and psychiatric co-disorders. While for some aspects evidence is rather good, for others data are conflicting. In the era of personalized medicine and in light of potent biological treatment options, it appears adequate to treat patients acknowledging their sex. Within this review, we summarize current knowledge of gender-

karger@karger.com

www.karger.com/dig

(C) 2020 S. Karger AG, Base

Karger!
Luc Biedermann, MD

Department of Gastroenterology and Hepatology University Hospital Zurich

Rämistrasse 100, CH-8091 Zurich (Switzerland)

E-Mail luc.biedermann@usz.ch 
specific differences in IBD and IBD management. We further highlight the most clinically relevant gender-specific aspects. Thereby we provide gastroenterologists with a roadmap of how to take gender into account when dealing with IBD patients.

\section{Epidemiology}

Immune-mediated diseases typically show a female preponderance. Looking at all autoimmune diseases combined, 8 of 10 patients are females [3-5]. Such female predominance is particularly seen for diseases such as Sjogren's syndrome or systemic lupus erythematosus. In gastrointestinal disease, primary biliary cholangitis and celiac disease are considerably more frequent in women than men. However, gender-specific differences are much less prominent in other immune-mediated disorders such as sarcoidosis, type 1 diabetes, and IBD $[5,6]$. Type 1 diabetes indeed is the only major organ-specific autoimmune disorder without a strong female bias; in contrast, a considerable male excess is seen in patients aged 15-40 years [7]. In IBD, gender-specific differences have been reported for Crohn's disease (CD), but not ulcerative colitis (UC), although data are conflicting and possibly depend on geographic areas. In Europe and the United States, CD prevalence appears to be higher in females than in males [8-13], while in Asia the opposite has been observed [14-16]. Early-onset CD ( $<16$ years) has been reported to be more frequent in males than females (20 vs. 12\%) [17]. A recent large investigation revealed an even more complex relation between sex and IBD epidemiology [18]. Young females at the age of 10-14 years showed a significantly lower risk for $\mathrm{CD}$ compared to men. A reduction in CD incidence of up to $20 \%$ has been reported. In contrast, females with an age of 25-29 years and particularly those older than 35 years are more prone to CD compared to their male counterparts. An increased risk of up to $40 \%$ has been observed [18]. Older males ( $>45$ years) appear to have a $20 \%$ higher incidence rate of UC compared to women [18]. These results have potential clinical implications. Since older male patients are more likely to suffer from the de novo UC, this diagnosis has to be considered particularly in elderly men with a chronic colonic inflammation of unknown etiology. However, data on potentially lower rates of IBD in young females should be interpreted cautiously, and diagnostic evaluation should be based on clinical presentation rather than reported incidence rates. This is particularly true in light of the significantly increased diagnostic delay for female patients [19]. Such a diagnostic delay is a problem in the female IBD population and has potentially deleterious consequences. A diagnostic delay has been associated with increased rates of complications in IBD and higher risk for CD-related intestinal surgery [20].

\section{Environmental Factors}

The reasons for the abovementioned gender-specific differences in IBD epidemiology remain unclear; genetic predisposition and different exposition to environmental factors are possible explanations [21]. At least, appendectomy and smoking are associated with an increased risk of $\mathrm{CD}$ in females $[6,22,23]$. Smoking has been a well-established and widely accepted risk factor for the development and progression of CD. While traditionally, smoking was more frequently observed in males across all age groups, this picture has changed quite dramatically in recent years. Numbers of smoking females, particularly those at younger age, have been steadily increasing. Currently, the highest smoking rates among IBD patients have been observed in middle-aged female CD subjects. The reported rate of $51.7 \%$ is higher than that seen in male counterparts as well as in the ageand sex-matched general population (26.6\%) [24]. Accordingly, a Dutch study revealed that more women than men are current smokers in the IBD population [17]. Long time ago, the following dogma was established and has been supported since: smoking is protective in UC, while it has deleterious effects in CD patients. However, the relation between smoking and IBD may be more complex than previously thought. Moreover, it appears to be gender-specific. Cosnes et al. [25] identified a protective effect of smoking in terms of UC development and disease course in male patients only. Moreover, a decrease in the need for immunosuppressive treatment was seen in smoking male patients, but not females [25]. In CD, the deleterious effects of smoking were seen in females, but not in males [25]. Female IBD patients probably have the highest benefit from smoking cessation and should be encouraged to stop smoking, in both UC and CD. Given the excess rates of smoking CD females [24], smoking cessation programs should be targeting those first.

A plethora of other gender-specific environmental factors potentially contribute to the development of IBD and disease complications. There appear to be considerable differences in terms of substance exposure between men and women, such as seen for drugs, chemical substances 
related to occupation, sunlight and vitamin $\mathrm{D}$, lifestyle factors including sleep, and shiftwork. However, the specific contribution of these factors to IBD has yet to be determined in more detail. Of note, hormone exposure during childhood, puberty, and menopause/andropause might play a role in IBD pathogenesis and disease course [6]. A clear gender-specific association with IBD has been established for antibiotics and appendectomy. Antibiotic use is more frequently reported among male patients, and boys may develop IBD more often after intake of antibiotics [26]. Appendectomy has been linked to a higher risk of CD in female patients [22]. The microbiome has been increasingly recognized as a key player in the pathogenesis of IBD [27]. Gender-specific differences in the microbiota composition have been described [28]. However, their specific contribution to the development and disease course of IBD remains elusive.

\section{Genetics}

Female preponderance appears to be higher in familial compared to sporadic IBD cases (61 vs. 54\%) [29]. Moreover, higher female-to-female transmission rates have been identified (compared to female-to-male transmission) [29]. This so-called female imprinting was specifically seen in CD. These findings shed light on a possible gender-specific genetic predisposition. In addition, several known susceptibility gene variants have been linked to a gender-specific risk increase/decrease for IBD. Among those are R30Q DLG5 in CD (male-specific risk), IL-23R variant L310P (protects women, but not men from developing UC), and a single nucleotide polymorphism in the promoter region of IL-10 (increased risk for UC in females) [30-33]. Mechanistic explanations for these differences are however lacking. A further mechanism for gender-specific differences in IBD genetics is related to X-chromosome abnormalities. X-chromosome abnormalities have been increasingly recognized as a possible contributor to autoimmunity $[34,35]$. Loss of the $\mathrm{X}$-chromosome in peripheral $\mathrm{T}$ - and B-lymphocytes has been associated with various immune-mediated disorders such as primary biliary cholangitis, autoimmune thyroid disease, Reynolds syndrome, and systemic sclerosis $[34,36]$. Loss of specific X-linked genes might result in the formation of autoantibodies [36]. If a similar mechanism is involved in IBD remains unknown. Of note and in accordance with this hypothesis, Turner syndrome, a disease where $\mathrm{X}$-monosomy occurs in every cell, is associated with an increased rate of IBD [37].

\section{Disease Activity and Phenotype}

Data regarding the influence of gender on disease activity and disease course are conflicting: in some studies, no association has been found, while in others male sex has been identified as an independent prognostic factor for severe disease $[38,39]$. Some studies - however - reported higher rates of remission in males and increased disease activity in females [40,41]. Data are more consistent when it comes to extraintestinal manifestations (EIM). EIM represent 1 important aspect of disease burden and IBD activity and show a well-established gender-specific distribution. While peripheral joint affections and skin manifestations such as erythema nodosum, pyoderma gangrenosum, and eye disorders are more frequently encountered in females, primary sclerosing cholangitis and ankylosing spondylitis are more common in males [42]. Overall, EIM are more common in female IBD patients [17].

IBD phenotype and location also show gender-specific differences. Our Swiss group recently described an association between sex and upper gastrointestinal tract involvement (L4 according to Montreal classification) [43]. Male sex and young age were identified as the main risk factors for the involvement of the upper gastrointestinal tract in CD patients [43]. In another study, male sex has been significantly associated with ileal disease in CD (28 vs. $20 \%$ in females) [17]. These findings suggest that IBD presents differently in men and women.

\section{Disease Complications}

For some IBD-related complications, a clear association with male or female sex has been reported. Colon cancer is more frequent in male IBD patients [44]. In addition, mortality from colorectal cancer appears to be higher in men than in women [45]. On the other hand, pulmonary complications show a higher mortality in female CD patients [46]. For other complications, genderspecificity is less clear and data are conflicting. A large prospective study from the Netherlands including 1,106 patients with CD and UC and a mean follow-up of 7 years did not identify gender as prognostic factor for the development of IBD complications. These complications included surgery, cumulative medication use, disease recurrence after surgery, and disease severity [38]. In contrast, a smaller study from Israel with $260 \mathrm{CD}$ patients and a follow-up of 12 years revealed 2 independent prognostic factors for the development of complications: smoking and male sex. The latter showed an OR of 2.6 [39]. In line 
Fig. 1. Synopsis of gender-specific treatment considerations. ADA, adalimumab.

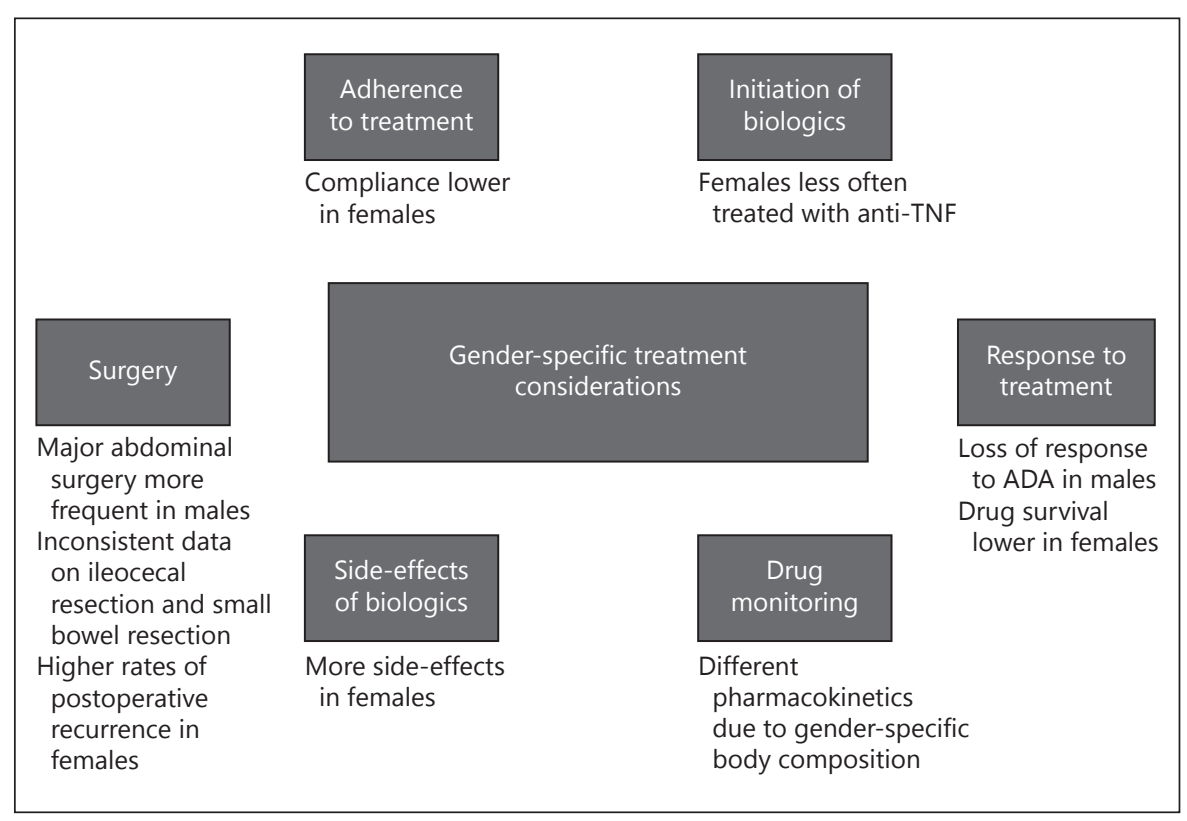

with these findings, a study from Mayo Clinic revealed male sex as an independent predictive factor for major abdominal surgery including bowel resection and ileocecal resection [47]. The Dutch IBD biobank - however demonstrated increased rates of small bowel and ileocecal resection in female patients [17].

Osteopenia and osteoporosis represent possible IBD-related complications that are gender-specific. Counterintuitively, osteopenia and osteoporosis were more frequently reported in male (55.9\%) than female IBD patients (29.6\%) in a retrospective single-center study from Germany (with dual-energy X-ray absorptiometry scans available for 174 patients). The gender-specific difference was mainly due to different rates of osteopenia rather than osteoporosis [48]. Similar findings have been reported in studies from Japan, the UK, and the Netherlands. Screening for the presence of osteopenia and osteoporosis is important in IBD patients and recommended by current society guidelines. Based on these findings, screening should be particularly promoted in male patients. However, a recent analysis of the Swiss IBD cohort revealed widely differing screening rates with rates as low as $11 \%$ in some centers [49].

\section{Treatment and Adherence}

Gender-specific differences are most impactful when it comes to IBD management. Indeed, use of and response to IBD treatment seem to vary between men and women regardless of intestinal disease activity, a fact that raises concerns about an adequate assessment of patients' disease presentation and progression as well as the physician-derived integration of results from diagnostic testing. Although data are limited, the following findings have been reported. Females are considered to receive no specific IBD treatment in a higher proportion than males [40]. In addition to medical treatment, major abdominal surgeries appear to be done more often in men than women, although data on intestinal resection and ileocecal resection are conflicting as previously mentioned [17, 47 , 50]. In the Dutch COIN study, there was no large genderspecific difference regarding IBD treatment. Still, male CD patients received prednisone more often [17].

No clear trend has been identified regarding anti-tumor necrosis factor outcome in 2 studies $[51,52]$. However, a shorter time until loss of response has been associated with male sex in patients treated with adalimumab. In addition, dose intensification was more often needed in men than in women [51]. Male gender was identified as an independent predictor of loss of response and need for dose intensification, together with known risk factors such as smoking, family history, isolated colonic disease, EIM, and longer disease duration [51]. In contrast, a more recent investigation with a median follow-up of 6 years revealed that drug survival was higher in males compared to females ( 48.1 vs. $30.8 \%, p=$ 0.016 ). This might be attributed to higher rates of side effects to biologics in females than males [53]. Female 
Table 1. Most important aspects that are relevant in daily clinical practice when dealing with gender-specific issues

\begin{tabular}{|c|c|}
\hline Dimension & Gender-specific difference \\
\hline Epidemiology & $\begin{array}{l}\text { Higher rates of CD in females in EU and US } \\
\text { Higher rates of CD in males in Asia } \\
\text { Young females with lower risk for CD, older } \\
\text { females with higher risk } \\
\text { Older males with higher risk for UC }\end{array}$ \\
\hline $\begin{array}{l}\text { Environmental } \\
\text { factors }\end{array}$ & $\begin{array}{l}\text { Appendectomy and smoking in females } \\
\text { Antibiotic use in males }\end{array}$ \\
\hline Genetics & $\begin{array}{l}\text { Female imprinting in familial IBD } \\
\text { Susceptibility gene variants such as IL-23R } \\
\text { variant L310P (protects women but not men } \\
\text { from getting UC) } \\
\text { X-chromosome abnormalities }\end{array}$ \\
\hline $\begin{array}{l}\text { Disease activity } \\
\text { and phenotype }\end{array}$ & $\begin{array}{l}\text { EIM more frequent in females } \\
\text { Upper GI involvement in males } \\
\text { Ileal disease more frequent in males }\end{array}$ \\
\hline $\begin{array}{l}\text { Disease } \\
\text { complications }\end{array}$ & $\begin{array}{l}\text { Higher risk and mortality for CRC in males } \\
\text { Higher mortality of pulmonary complications } \\
\text { in females } \\
\text { Osteopenia more frequent in males }\end{array}$ \\
\hline Treatment & $\begin{array}{l}\text { Male gender associated with loss of response } \\
\text { to anti-TNF } \\
\text { Drug survival higher in males } \\
\text { More side-effects to anti-TNF in females } \\
\text { Adherence rates lower in females }\end{array}$ \\
\hline $\begin{array}{l}\text { Psychosocial } \\
\text { factors }\end{array}$ & $\begin{array}{l}\text { Depression more frequent in females } \\
\text { Self-reported QoL lower in females } \\
\text { Fatigue more frequent in females }\end{array}$ \\
\hline
\end{tabular}

$\mathrm{CD}$, Crohn's disease; UC, ulcerative colitis; IBD, inflammatory bowel disease; EIM, extraintestinal manifestations; IL, interleukin; CRC, colorectal cancer; TNF, tumor necrosis factor; QoL, quality of life.

gender (together with smoking) was identified as an independent prognostic factor for nonadherence to biological treatment [54]. Neglecting these gender-specific aspects may potentially result in suboptimal treatment of men, women, or both. Figure 1 summarizes factors that need to be considered, when it comes to genderspecific treatment approaches.

\section{Psychological Factors}

While data regarding epidemiology, disease course, and treatment can be conflicting, data on psychosocial functioning and psychiatric co-disorders in IBD seem to be quite consistent. The fact that prevalence of depression in IBD is higher in women than in men is not surprising given comparable results in the general population [55]. Women tend to use the healthcare system more often and absence from work seems to be higher [56]. Self-reported quality of life is lower in females than in males [56-58]. Fatigue represents an important clinical symptom that is often underrecognized among physicians involved in IBD care. Several studies have revealed that fatigue is highly frequent in IBD [59-62]. Of note, there is a wellestablished gender-specific difference in terms of fatigue: female subjects tend to have a higher prevalence of fatigue and this finding is reported across all age groups (Swiss IBD cohort study, unpublished data). These findings are irrespective of the presence or absence of anemia, a typical contributor to the symptoms of fatigue [60]. Moreover, gender-specific difference in the prevalence of fatigue is independent of underlying disease activity [60]. Both frequency and intensity of fatigue are more prominent in the female population. IBD further has a negative impact on body image, more so in females than in males $[63,64]$. Reduced sexual activity is more frequently reported in female than male IBD patients ( 66.3 vs. $40.5 \%$, $p<0.001$ ) [64]. It is essential that these aspects are not neglected in daily clinical practice.

\section{Clinical Implications of Gender Differences}

The most important aspects that are relevant for gastroenterologists, when dealing with gender-specific issues in daily practice, are summarized in Table 1 . In the era of personalized medicine and in light of potent biological treatment options, it may not be adequate anymore to treat patients without acknowledging their sex. Tailored treatment strategies for individual patients are needed, and for this, sex has to be taken into account as an important variable in addition to disease activity, phenotype, location, behavior, presence of complications, EIM, and so on. While sex as a modulating factor in IBD development and progression has been increasingly recognized in recent years, data are as of yet conflicting. Most evident and probably most clinically relevant are the following aspects: (1) smoking is a problem and risk factor particularly in females suffering from CD; (2) osteopenia is more frequently observed in men than women; and (3) side-effects from biologics are higher in females than males, which is presumably among the major driving forces for a lower treatment adherence in women. Based on these findings, clinicians should (1) assess 
smoking status in women in particular and encourage smoking cessation in this patient population; (2) screen for osteopenia/osteoporosis especially in male IBD patients; and (3) consider women in particular to be nonadherent to biological treatment. Side-effects should be particularly inquired. These 3 simple recommendations are a first step toward a gender-specific IBD management and will improve patient care.

\section{Disclosure Statement}

T.G. has a consulting contract with Sanofi-Aventis, received a travel grant from Falk Pharma GmbH and Vifor, and an unrestricted research grant from Novartis. S.R.V. received consultant fees and unrestricted research grants from Abbott, Ferring, MSD,
Pfizer, Takeda, Tillots, UCB, Vifor and Falk Pharma GmbH. L.B. received consulting fees from Abbvie, MSD, Vifor, Ferring, Pfizer, Shire, Takeda, UCB, Janssen and travel grants from Abbvie, MSD, Vifor, Pfizer, Takeda. No company representative was involved in conception, writing, or financing of this study.

\section{Funding Sources}

There is no funding to declare.

\section{Author Contributions}

T.G. and L.B. drafted and wrote the manuscrcipt and created tables and figures. C.M., V.P., and S.R.V. provided critical input at any stage of writing and contributed to the literature research.

\section{References}

1 Kane SV, Sable K, Hanauer SB. The menstrual cycle and its effect on inflammatory bowel disease and irritable bowel syndrome: a prevalence study. Am J Gastroenterol. 1998 Oct; 93(10):1867-72.

2 Rosenblatt E, Kane S. Sex-Specific Issues in Inflammatory Bowel Disease. Gastroenterol Hepatol (N Y). 2015 Sep;11(9):592-601.

3 Fish EN. The X-files in immunity: sex-based differences predispose immune responses. Nat Rev Immunol. 2008 Sep;8(9):737-44.

4 Liang Y, Tsoi LC, Xing X, Beamer MA, Swindell WR, Sarkar MK, et al. A gene network regulated by the transcription factor VGLL3 as a promoter of sex-biased autoimmune diseases. Nat Immunol. 2017 Feb;18(2):152-60.

5 Whitacre CC. Sex differences in autoimmune disease. Nat Immunol. 2001 Sep;2(9):777-80.

6 Ngo ST, Steyn FJ, McCombe PA. Gender differences in autoimmune disease. Front Neuroendocrinol. 2014 Aug;35(3):347-69.

7 Gale EA, Gillespie KM. Diabetes and gender. Diabetologia. 2001 Jan;44(1):3-15.

8 Wagtmans MJ, Verspaget HW, Lamers CB, van Hogezand RA. Gender-related differences in the clinical course of Crohn's disease. Am J Gastroenterol. 2001 May;96(5):1541-6.

9 Kyle J. Crohn's disease in the northeastern and northern Isles of Scotland: an epidemiological review. Gastroenterology. 1992 Aug; 103(2):392-9.

10 Latour P, Louis E, Belaiche J. Incidence of inflammatory bowel disease in the area of Liège: a 3 years prospective study (1993-1996). Acta Gastroenterol Belg. 1998 Oct-Dec;61(4):410-3.

11 ShivanandaS, Peña AS, Nap M, Weterman IT, Mayberry JF, Ruitenberg EJ, et al. Epidemiology of Crohn's disease in Regio Leiden, The Netherlands. A population study from 1979 to 1983. Gastroenterology. 1987 Nov;93(5):96674.
12 Whelan G. Epidemiology of inflammatory bowel disease. Med Clin North Am. 1990 Jan; 74(1):1-12.

13 Brahme F, Lindström C, Wenckert A. Crohn's disease in a defined population. An epidemiological study of incidence, prevalence, mortality, and secular trends in the city of Malmö, Sweden. Gastroenterology. 1975 Aug;69(2): 342-51.

14 Prideaux L, Kamm MA, De Cruz PP, Chan FK, Ng SC. Inflammatory bowel disease in Asia: a systematic review. J Gastroenterol Hepatol. 2012 Aug;27(8):1266-80.

15 Yang SK, Loftus EV Jr, Sandborn WJ. Epidemiology of inflammatory bowel disease in Asia. Inflamm Bowel Dis. 2001 Aug;7(3):260-70.

16 Leong RW, Lau JY, Sung JJ. The epidemiology and phenotype of Crohn's disease in the Chinese population. Inflamm Bowel Dis. 2004 Sep;10(5):646-51.

17 Severs M, Spekhorst LM, Mangen MJ, Dijkstra G, Löwenberg M, Hoentjen F, et al. SexRelated Differences in Patients With Inflammatory Bowel Disease: Results of 2 Prospective Cohort Studies. Inflamm Bowel Dis. 2018 May;24(6):1298-306.

18 Shah SC, Khalili H, Gower-Rousseau C, Olen $\mathrm{O}$, Benchimol EI, Lynge E, et al. Sex-Based Differences in Incidence of Inflammatory Bowel Diseases-Pooled Analysis of PopulationBased Studies From Western Countries. Gastroenterology. 2018 Oct;155(4):1079-1089. e3.

19 Vavricka SR, Spigaglia SM, Rogler G, Pittet V, Michetti P, Felley C, et al.; Swiss IBD Cohort Study Group. Systematic evaluation of risk factors for diagnostic delay in inflammatory bowel disease. Inflamm Bowel Dis. $2012 \mathrm{Mar}$; 18(3):496-505.

20 Schoepfer AM, Dehlavi MA, Fournier N, Safroneeva E, Straumann A, Pittet V, et al.; IBD
Cohort Study Group. Diagnostic delay in Crohn's disease is associated with a complicated disease course and increased operation rate. Am J Gastroenterol. 2013 Nov; 108(11): 1744-53; quiz 1754.

21 Hausmann J, Blumenstein I. [Gender differences and inflammatory bowel disease]. Z Gastroenterol. 2015 Aug;53(8):774-8.

22 Andersson RE, Olaison G, Tysk C, Ekbom A. Appendectomy is followed by increased risk of Crohn's disease. Gastroenterology. 2003 Jan;124(1):40-6.

23 Lakatos PL, Vegh Z, Lovasz BD, David G, Pandur T, Erdelyi Z, et al. Is current smoking still an important environmental factor in inflammatory bowel diseases? Results from a population-based incident cohort. Inflamm Bowel Dis. 2013 Apr; 19(5):1010-7.

24 Biedermann L, Fournier N, Misselwitz B, Frei P, Zeitz J, Manser CN, et al.; Swiss Inflammatory Bowel Disease Cohort Study Group. High Rates of Smoking Especially in Female Crohn's Disease Patients and Low Use of Supportive Measures to Achieve Smoking Cessation-Data from the Swiss IBD Cohort Study. J Crohn's Colitis. 2015 Oct;9(10):81929.

25 Cosnes J, Nion-Larmurier I, Afchain P, Beaugerie L, Gendre JP. Gender differences in the response of colitis to smoking. Clin Gastroenterol Hepatol. 2004 Jan;2(1):41-8.

26 Kronman MP, Zaoutis TE, Haynes K, Feng R, Coffin SE. Antibiotic exposure and IBD development among children: a populationbased cohort study. Pediatrics. 2012 Oct; 130(4):e794-803.

27 Yilmaz B, Juillerat P, Øyås O, Ramon C, Bravo FD, Franc Y, et al.; Swiss IBD Cohort Investigators. Microbial network disturbances in relapsing refractory Crohn's disease. Nat Med. 2019 Feb;25(2):323-36. 
28 Bolnick DI, Snowberg LK, Hirsch PE, Lauber CL, Org E, Parks B, et al. Individual diet has sex-dependent effects on vertebrate gut microbiota. Nat Commun. 2014 Jul;5(1):4500.

29 Zelinkova Z, Stokkers PC, van der Linde K, Kuipers EJ, Peppelenbosch MP, van der Woude CP. Maternal imprinting and female predominance in familial Crohn's disease. J Crohn's Colitis. 2012 Aug;6(7):771-6.

30 Biank V, Friedrichs F, Babusukumar U, Wang T, Stoll M, Broeckel U, et al. DLG5 R30Q variant is a female-specific protective factor in pediatric onset Crohn's disease. Am J Gastroenterol. 2007 Feb;102(2):391-8.

31 Browning BL, Annese V, Barclay ML, Bingham SA, Brand S, Büning C, et al. Genderstratified analysis of DLG5 R30Q in 4707 patients with Crohn disease and 4973 controls from 12 Caucasian cohorts. J Med Genet. 2008 Jan;45(1):36-42.

32 Lin Z, Poritz L, Franke A, Li TY, Ruether A, Byrnes KA, et al. Genetic association of nonsynonymous variants of the IL23R with familial and sporadic inflammatory bowel disease in women. Dig Dis Sci. 2010 Mar;55(3):73946.

33 Tedde A, Laura Putignano A, Bagnoli S, Congregati $\mathrm{C}$, Milla $\mathrm{M}$, Sorbi $\mathrm{S}$, et al. Interleukin-10 promoter polymorphisms influence susceptibility to ulcerative colitis in a genderspecific manner. Scand J Gastroenterol. 2008; 43(6):712-8.

34 Svyryd Y, Hernández-Molina G, Vargas F, Sánchez-Guerrero J, Segovia DA, Mutchinick $\mathrm{OM}$. X chromosome monosomy in primary and overlapping autoimmune diseases. Autoimmun Rev. 2012 Mar;11(5):301-4.

35 Libert C, Dejager L, Pinheiro I. The X chromosome in immune functions: when a chromosome makes the difference. Nat Rev Immunol. 2010 Aug;10(8):594-604.

36 Invernizzi P, Miozzo M, Selmi C, Persani L, Battezzati PM, Zuin M, et al. X chromosome monosomy: a common mechanism for autoimmune diseases. J Immunol. 2005 Jul; 175(1) $575-8$.

37 Arulanantham K, Kramer MS, Gryboski JD. The association of inflammatory bowel disease and X chromosomal abnormality. Pediatrics. 1980 Jul;66(1):63-7.

38 Romberg-Camps MJ, Dagnelie PC, Kester AD, Hesselink-van de Kruijs MA, Cilissen M, Engels LG, et al. Influence of phenotype at diagnosis and of other potential prognostic factors on the course of inflammatory bowel disease. Am J Gastroenterol. 2009 Feb;104(2):371-83.

39 Mazor Y, Maza I, Kaufman E, Ben-Horin S, Karban A, Chowers Y, et al. Prediction of disease complication occurrence in Crohn's disease using phenotype and genotype parameters at diagnosis. J Crohn's Colitis. 2011 Dec; 5(6):592-7.

40 Blumenstein I, Herrmann E, Filmann N, Zosel C, Tacke W, Bock H, et al. Female patients suffering from inflammatory bowel diseases are treated less frequently with immunosuppressive medication and have a higher disease activity: a subgroup analysis of a large multicentre, prospective, internet-based study. Crohn's Colitis. 2011 Jun;5(3):203-10.

41 Bokemeyer B, Hardt J, Hüppe D, Prenzler A, Conrad S, Düffelmeyer M, et al. Clinical status, psychosocial impairments, medical treatment and health care costs for patients with inflammatory bowel disease (IBD) in Germany: an online IBD registry. J Crohn's Colitis. 2013 Jun;7(5):355-68.

42 Bernstein CN, Blanchard JF, Rawsthorne P, $\mathrm{Yu} \mathrm{N}$. The prevalence of extraintestinal diseases in inflammatory bowel disease: a population-based study. Am J Gastroenterol. 2001 Apr;96(4):1116-22.

43 Greuter T, Piller A, Fournier N, Safroneeva E, Straumann A, Biedermann L, et al.; Swiss IBD Cohort Study Group. Upper Gastrointestinal Tract Involvement in Crohn's Disease: Frequency, Risk Factors, and Disease Course. J Crohn's Colitis. 2018 Nov; 12(12): 1399-409.

44 Söderlund S, Brandt L, Lapidus A, Karlén P. Broström $\mathrm{O}$, Löfberg R, et al. Decreasing timetrends of colorectal cancer in a large cohort of patients with inflammatory bowel disease. Gastroenterology. 2009 May;136(5):1561-7; quiz 1818-9.

45 Sebastian S, Hernández V, Myrelid P, Kariv R, Tsianos E, Toruner M, et al. Colorectal cancer in inflammatory bowel disease: results of the 3rd ECCO pathogenesis scientific workshop (I). J Crohn's Colitis. 2014 Jan;8(1):5-18.

46 Jussila A, Virta LJ, Pukkala E, Färkkilä MA. Mortality and causes of death in patients with inflammatory bowel disease: a nationwide register study in Finland. J Crohn's Colitis. 2014 Sep;8(9):1088-96.

47 Peyrin-Biroulet L, Harmsen WS, Tremaine WJ, Zinsmeister AR, Sandborn WJ, Loftus EV Jr. Surgery in a population-based cohort of Crohn's disease from Olmsted County, Minnesota (1970-2004). Am J Gastroenterol. 2012 Nov;107(11):1693-701.

48 Walldorf J, Krummenerl A, Engler K, Busch J, Dollinger MM, Seufferlein T, et al. Health care for osteoporosis in inflammatory bowel disease: unmet needs in care of male patients? J Crohn's Colitis. 2013 Dec;7(11):901-7.

49 Schüle S, Rossel JB, Frey D, Biedermann L, Scharl M, Zeitz J, et al.; Swiss IBD cohort study. Widely differing screening and treatment practice for osteoporosis in patients with inflammatory bowel diseases in the Swiss IBD cohort study. Medicine (Baltimore). 2017 Jun;96(22):e6788.

50 Samuel S, Ingle SB, Dhillon S, Yadav S, Harmsen WS, Zinsmeister AR, et al. Cumulative incidence and risk factors for hospitalization and surgery in a population-based cohort of ulcerative colitis. Inflamm Bowel Dis. 2013 Aug;19(9):1858-66.

51 Billioud V, Sandborn WJ, Peyrin-Biroulet L. Loss of response and need for adalimumab dose intensification in Crohn's disease: a systematic review. Am J Gastroenterol. 2011 Apr;106(4):674-84.
52 Sprakes MB, Ford AC, Warren L, Greer D, Hamlin J. Efficacy, tolerability, and predictors of response to infliximab therapy for Crohn's disease: a large single centre experience. J Crohn's Colitis. 2012 Mar;6(2):143-53.

53 Lie MR, Kreijne JE, van der Woude CJ. Sex Is Associated with Adalimumab Side Effects and Drug Survival in Patients with Crohn's Disease. Inflamm Bowel Dis. 2017 Jan;23(1):7581.

54 Lopez A, Billioud V, Peyrin-Biroulet C, Peyrin-Biroulet L. Adherence to anti-TNF therapy in inflammatory bowel diseases: a systematic review. Inflamm Bowel Dis. 2013 Jun; 19(7):1528-33.

55 Häuser W, Janke KH, Klump B, Hinz A. Anxiety and depression in patients with inflammatory bowel disease: comparisons with chronic liver disease patients and the general population. Inflamm Bowel Dis. 2011 Feb; 17(2):621-32.

56 Nurmi E, Haapamäki J, Paavilainen E, Rantanen A, Hillilä M, Arkkila P. The burden of inflammatory bowel disease on health care utilization and quality of life. Scand J Gastroenterol. 2013 Jan;48(1):51-7.

57 Graff LA, Walker JR, Lix L, Clara I, Rawsthorne P, Rogala L, et al. The relationship of inflammatory bowel disease type and activity to psychological functioning and quality of life. Clin Gastroenterol Hepatol. 2006 Dec; 4(12):1491-501.

58 Hauser G, Tkalcić M, Stimac D, Milić S, Sincić BM. Gender related differences in quality of life and affective status in patients with inflammatory bowel disease. Coll Antropol. 2011 Sep;35(Suppl 2):203-7.

59 Saraiva S, Cortez-Pinto J, Barosa R, Castela J, Moleiro J, Rosa I, et al. Evaluation of fatigue in inflammatory bowel disease - a useful tool in daily practice. Scand J Gastroenterol. 2019 Apr;54(4):465-70.

60 Bager P, Befrits R, Wikman O, Lindgren S, Moum B, Hjortswang H, et al. Fatigue in outpatients with inflammatory bowel disease is common and multifactorial. Aliment Pharmacol Ther. 2012 Jan;35(1):133-41.

61 Le Berre C, Peyrin-Biroulet L, Buisson A, Olympie A, Ravel MH, Bienenfeld C, et al. Impact of inflammatory bowel diseases on working life: A French nationwide survey. Dig Liver Dis. 2019 Jul;51(7):961-6.

62 Van de Vijver E, Van Gils A, Beckers L, Van Driessche Y, Moes ND, van Rheenen PF. Fatigue in children and adolescents with inflammatory bowel disease. World J Gastroenterol. 2019 Feb;25(5):632-43.

63 Trindade IA, Ferreira C, Pinto-Gouveia J. The effects of body image impairment on the quality of life of non-operated Portuguese female IBD patients. Qual Life Res. 2017 Feb;26(2): 429-36.

64 Jedel S, Hood MM, Keshavarzian A. Getting personal: a review of sexual functioning, body image, and their impact on quality of life in patients with inflammatory bowel disease. Inflamm Bowel Dis. 2015 Apr;21(4):923-38. 